\title{
ANÁLISE DA PREDISPOSIÇÃO À EROSÃO LAMINAR (ENTRESSULCOS) EM UM PLANOSSOLO NA VÁRZEA DO AGUDO, AGUDO-RS
}

\author{
Analysis of the Predisposition to the \\ Laminate Erosion in a Planossolo in Várzea \\ do Agudo, Agudo-Rs
}

Carlos Rudolfo Paul e Mauro Kumpfer Werlang mkwerlang@smail.ufsm.br

Universidade Federal de Santa Maria

\section{RESUMO}

Este trabalho objetivou analisar a predisposição à erosão laminar em um Planossolo, localizado na Várzea do Agudo, interior do município de Agudo, Rio Grande do Sul. Realizou-se um estudo comparativo entre alguns dos índices físicos do solo em uma área de lavoura e outra de mata. A metodologia foi embasada na proposição da análise sistêmica da paisagem e no método dedutivo. Os principais procedimentos técnicos foram a realização de ensaios de infiltração, coleta de amostras deformadas de solo e indeformadas que serviram para a determinação da distribuição do tamanho de partículas, da densidade do solo, da densidade de partículas, do índice de vazios, da porosidade total, da estabilidade de agregados e da matéria orgânica. Concluiu-se que a área ocupada por lavoura apresenta maior suscetibilidade à erosão hídrica, em comparação com a área de mata.

Palavras-chave: índices físicos do solo, erosão laminar, Planossolo, Várzea do Agudo. 


\section{Abstract}

This study aims to evaluate predisposition to erosion laminar in a Planosol, located in the Várzea of Agudo, interior of municipality Agudo, state of Rio Grande do Sul. We conducted a comparative study of some of the physical indices of soil in an area of plantations and forests. The methodology was based on the proposition of systemic analysis of the landscape and the deductive method. The main technical procedures were in testing of infiltration, collecting soil samples deformed and undeformed who served for the determination of particle size distribution, of soil density, particle density, the void volume, the soil porosity, aggregate stability and organic matter. It was concluded that the area occupied by plantation are more susceptible to erosion in comparison with the area of forest.

Key words: physical indices of soil, erosion laminar, Planosol, Várzea of Agudo.

\section{Introdução}

Ao se tratar da temática referente à erosão dos solos, é importante estabelecer a relação do uso e exploração desse recurso natural com a forma de ocupação do espaço geográfico. De maneira geral, pode-se afirmar que a produção do espaço geográfico está diretamente ligada à ação humana, sendo resultado dessa ação e continuamente transformado pelas relações sociais que se desenvolvem. Essa concepção é primordial para se trabalhar com diversos assuntos da ciência geográfica, porém, para a questão ambiental, ganha uma importância ainda maior, pois explica a relação homem-natureza, possibilitando um maior entendimento da atual ocupação de um espaço e o uso que está se dando a ele. Além disso, pode-se considerar que é na natureza, ou seja, no ambiente físico, que se materializam as relações sociais produtoras desse espaço.

O espaço geográfico é utilizado pelo homem em seu beneficio, sendo este um assunto que tem despertado o interesse de vários pesquisadores, principalmente pelo fato de a ocupação representar riscos de deterioração ao meio ambiente, gerando uma pressão sobre os recursos naturais. Assim, ao se relacionar o tema erosão com o uso do solo é possível obter uma resposta, não só da atual dinâmica desse espaço, mas também da eventual degradação que possa ocorrer no futuro.

No que se refere às ocorrências da erosão, esta acontece em função de diversos agentes, porém um dos principais é a água, que atua 
através do escoamento superficial (GUERRA, 2007). Têm importância fundamental também as propriedades físicas do solo, que devem ser analisadas em conjunto com a ação do agente erosivo. Conforme Silva (2001), a análise dos processos erosivos pressupõe um conhecimento acerca das condições naturais existentes que, combinadas, determinam valores diferenciados de taxas de erosão. Ainda de acordo com Silva; Guerra (2001), os principais fatores que devem ser observados são a erosividade da chuva, as propriedades do solo, a cobertura vegetal e as características das vertentes.

A erosão tem se tornado mais grave à medida que não se tomam as medidas necessárias para a sua contenção, ou quando são insuficientes as políticas de manejo de áreas degradadas ou susceptíveis à degradação.

Após esta breve problematização a respeito da erosão, coloca-se outra questão fundamental como justificativa deste estudo: a importância do solo como recurso natural. A importância desse recurso está inicialmente associada à grande biodiversidade que ele pode sustentar e a relação desta biodiversidade com a sua fertilidade natural. Nesse sentido, o solo pode sustentar diversas formas de vida, pois é capaz de armazenar, em seus espaços porosos, água e nutrientes para as plantas. O solo está em uma posição que se sobrepõe à litosfera, hidrosfera e atmosfera, possuindo interfaces nas matérias sólida, líquida e gasosa. Somente com o suprimento adequado desses elementos (ar, água e elementos minerais) é que se desenvolvem plantas fotossintetizantes de ecossistemas terrestres (AZEVEDO, 2004).

Seguindo nesse raciocínio e, ao mesmo tempo, levando-se em consideração a grande importância econômica que a atividade orizícola tem para o município de Agudo-RS, o trabalho objetiva contribuir para um estudo comparativo entre os índices físicos do solo numa área de lavoura e outra de mata e avaliar o impacto acerca da erosão do solo. Como já mencionado, o solo comporta grande biodiversidade, porém o uso intensivo da agricultura com agroquímicos causa um declínio da sua biodiversidade e, consequentemente, da sua fertilidade natural.

\section{Localização E Caracterização Da Área}

A área de estudo está situada na localidade de Várzea do Agudo, oeste do município de Agudo-RS, na região central do estado Rio Grande do Sul. A figura 1 mostra a localização da área de Várzea do Agudo. 


\section{ciência'natura UFSM, 34(2)}

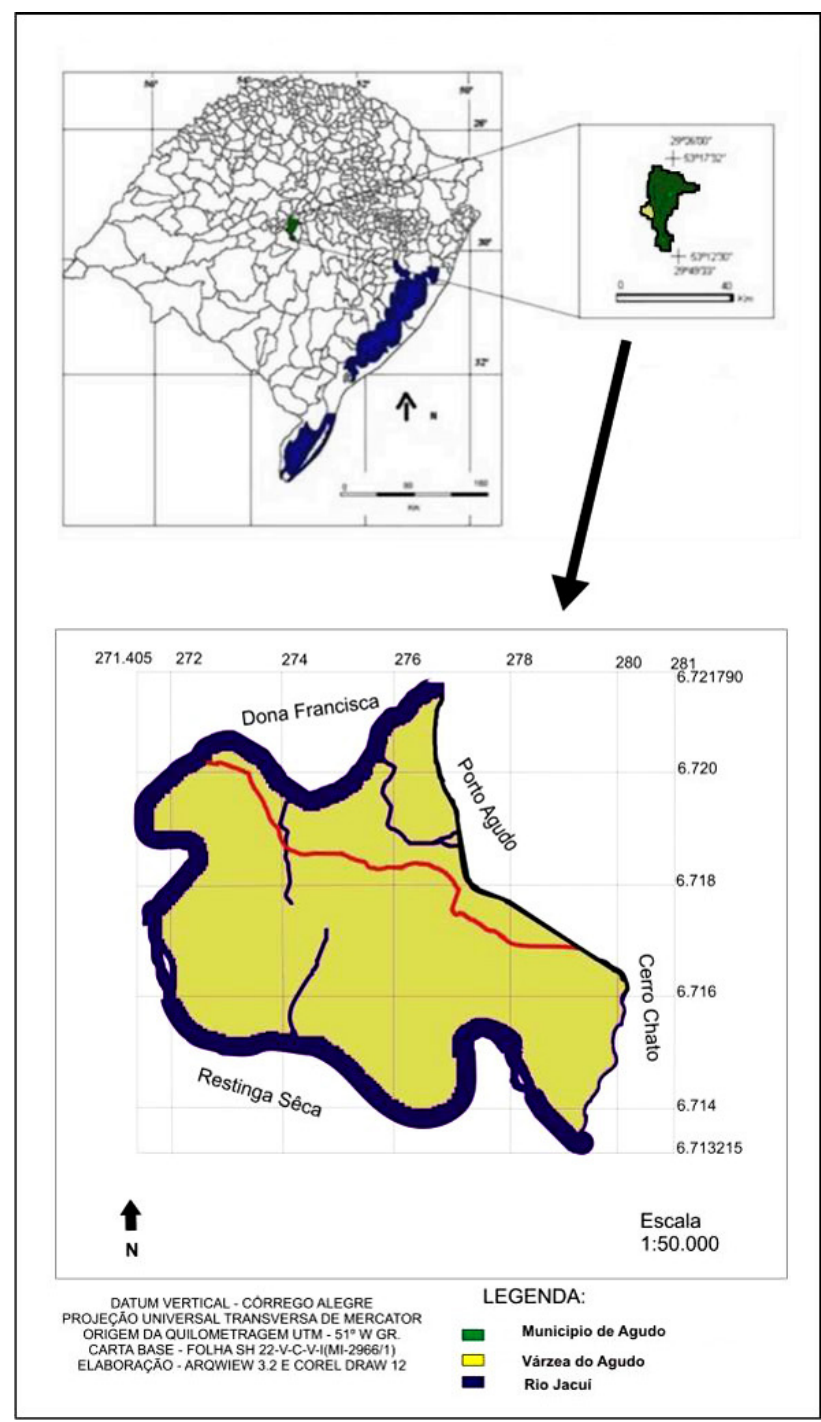

Figura 1. Localização da área de Várzea do Agudo em relação ao município de Agudo-RS

O município de Agudo-RS está localizado entre as latitudes de $29^{\circ}$ $26^{\prime} \circ 0^{\prime \prime}$ e $29^{\circ} 49^{\prime} 33^{\prime \prime} \mathrm{S}$ e entre as longitudes de $53^{\circ} 12^{\prime} 30^{\prime \prime}$ e $53^{\circ} 17^{\prime} 32^{\prime \prime} \mathrm{W}$.

O município caracteriza-se por estar situado numa área de transição entre a Depressão Periférica Sul-riograndense (ROSS,1996), próximo ao rebordo Planalto da Bacia Sedimentar do Paraná. Apresenta 
relevo com declividades acentuadas em grande parte do seu território, principalmente nas áreas norte e leste do município. Já nas áreas ao sul e oeste, predominam características de relevo associadas à Depressão Periférica Sul-riograndense, com topografia plana a suavemente ondulada.

Em relação à geologia, no município, estão presentes as Formações Sanga do Cabral, Santa Maria, Caturrita, Serra Geral e Depósitos aluvionares.

O clima, com base na classificação de Köppen (1944 apud Ayoade, 1986), enquadra-se como sendo mesotérmico brando Cfa. As precipitações são regulares durante todo o ano, não apresentando estação seca (Ayoade,1986). Em relação à hidrografia, pertence ao sistema hídrico da bacia do rio Jacuí.

Parte da área do município está inserida no domínio da floresta estacional decidual (FIBGE, 1986) e outra na dos campos com capões e matas galerias (VIEIRA, 1984). No que se refere à vegetação e ao uso atual, o município sofreu significativas alterações na cobertura original da vegetação. Na porção representada pelo Rebordo do Planalto, os empreendimentos agrários impuseram forte modificação na vegetação, apresentando apenas remanescentes da floresta estacional decidual. Os agrupamentos remanescentes da cobertura vegetal encontram-se nas partes íngremes das encostas.

Nas áreas em que os processos erosivos esculpiram colinas alongadas (coxilhas) em rochas paleozóicas da Bacia do Paraná, aparecem solos medianamente profundos como Argissolos. Nas áreas de terraços e planícies fluviais, onde a flutuação do lençol freático, associada à conformação da topografia, imprime maior influência sobre os processos pedogenéticos, ocorrem Gleissolos e Planossolos. Já em áreas do Rebordo, ocorrem Neossolos Litólicos e Cambissolos. Nos patamares e áreas mais planas, ocorrem, além de Argissolos Vermelhos e Nitossolos, alguns Latossolos.

O município possui uma área de $536,12 \mathrm{~km}^{2}$ e apresenta 16.722 habitantes (IBGE, 2010). Essa população distribui-se em 2.724 estabelecimentos agropecuários, que juntos somam uma área total de 43.795 ha, prevalecendo pequenas e médias propriedades, com predomínio de uma organização familiar. A agricultura é realizada por pequenos produtores rurais, com um módulo rural médio de 16,07 hectares. In- 
serido na Microrregião de Restinga Seca, Agudo faz divisa com Ibarama ao norte, Lagoa Bonita a noroeste, Cerro Branco ao leste e Paraíso do Sul ao sul. A porção norte tem uma economia baseada na atividade agrícola com o cultivo do fumo como principal produto. Nessa porção, predomina a fumicultura associada com outros cultivos que não utilizam grandes áreas de lavouras, concentrando uma agricultura familiar. Na porção sul, a cultura do fumo desenvolve-se em pequenas áreas de colinas, com topografia suave ondulada. Entretanto, a principal cultura da porção sul do município baseia-se no cultivo do arroz, ocupando as áreas de várzea.

\title{
2. Fudamentação Teórica
}

\subsection{O sistema solo}

Conforme Embrapa (2006, p.4), solo é:

\begin{abstract}
uma coleção de corpos naturais, constituídos por partes sólidas, líquidas e gasosas, tridimensionais, dinâmicos, formados por materiais minerais e orgânicos que ocupam a maior parte do manto superficial das extensões continentais do nosso planeta, contém matéria viva e podem ser vegetados na natureza onde ocorrem e podem, eventualmente, terem sido modificados por interferências antrópicas.
\end{abstract}

O solo pode ser visto como um sistema, em que há interação entre diversos elementos, dentre eles microorganismos, vegetação e água. Porém, quando analisado como um produto, ele é, segundo Resende et al (1995), oriundo da ação do clima, dos organismos e do material de origem (rocha).

Azevedo (2006) também coloca que o solo é como um sistema, sendo constituído por três fases, a sólida, a líquida e a gasosa. A fase gasosa é constituída por carbono e, em menor quantidade, por oxigênio; a fase líquida é caracterizada por toda a umidade nele presente; e a fase sólida, pelas partículas minerais e orgânicas. Ainda conforme Azevedo (2006), o solo é considerado como um sistema aberto, pois troca matéria e energia com o meio. A troca de energia ocorre através do aquecimento do solo pelo Sol e este por sua vez aquecendo o ar próximo à superfície. Já a troca de matéria ocorre através da precipitação e evaporação da umidade do solo.

Para complementar essa ideia, Nascimento; Giasson; e Inda (2004) 
classificam o solo como um sistema dentro da teoria holística'. Para eles, o sistema solo é intensamente dinâmico, sendo constantemente perturbado por forças internas e externas, ocorrendo, dessa maneira, adições, remoções, transferências e transformações de diversos elementos, como matéria e energia. Essas forças internas e externas podem ser entendidas como sendo os diversos elementos, como, minerais, plantas, microorganismos, compostos orgânicos e o ambiente externo, este representado pela ação antrópica.

Nesse sentido, pode-se afirmar que o solo é um corpo natural organizado e que dissipa entropia para o ambiente externo. Nesse sentido, Nascimento; Giasson; e Inda (2004) observam que é importante entender o solo dessa forma, pois possibilita o estabelecimento de relações entre os fatores ambientais e os diferentes tipos de solos, permitindo avaliar o potencial de uso das terras para diversos fins e diagnosticar os possíveis efeitos da intervenção humana. Esses fatores ambientais são representados, principalmente, pelo material de origem, pelo clima, pelo relevo e pelos organismos vivos. Esses fatores, quando combinados de maneiras diversas, originam diferentes tipos de solos.

Os processos pedogenéticos podem ser classificados em físicos, químicos e biológicos, cuja ação é condicionada pelos fatores pedogenéticos. Estes, por sua vez, compreendem o material de origem, o clima, o relevo, os organismos vivos, além do tempo de atuação dos processos pedogentéticos. Da ação dos processos pedogenéticos sobre o material de origem e em continuidade no solo, constitui-se o que se denomina intemperização (JENNY, 1992). A intensidade da intemperização varia conforme as diferentes regiões do globo terrestre, pois as condições de equilíbrio também variam de uma região para outra. Esse equilíbrio depende da constituição mineralógica dos materiais originais e das condições ambientais, representadas pelos demais fatores pedogenéticos, que regulam a ação dos processos pedogenéticos. Durante o intemperismo,

\footnotetext{
' De acordo com a concepção holística (do Grego, holos = totalidade), um sistema consiste num todo organizado, constituído por um conjunto de componentes interdependentes que atua integradamente, de maneira que a alteração de um componente afeta os demais, ou seja, a maneira como as partes estão integradas no todo é mais importante do que as partes isoladas (NASCIMENTO; GIASSON; INDA ( 2004)).
} 
a decomposição da rocha e a formação do solo fundem-se. A decomposição propicia caminho para a formação do solo (FONSECA, 1999).

\subsection{Erosão no contexto da paisagem}

A erosão pode ser entendida como um processo mecânico que age na superfície e em profundidade, sob determinadas condições físicas. Traduz-se na desagregação, transporte e deposição de partículas do solo, subsolo e rocha em decomposição, através dos agentes águas correntes, vento ou geleiras. A erosão hídrica desenvolve-se a partir da formação de um canal em que há concentração do escoamento; em seguida, ocorre incremento rápido em profundidade e largura, movendo a cabeceira para montante. O processo erosivo atua de diversas formas e com intensidades variadas e é dependente do uso e do manejo que se dá ao solo.

A formação do solo ocorre através de processos pedogenéticos em que agentes físicos, químicos e biológicos atuam sobre um determinado material de origem durante centenas de milhares de anos. A água é um dos principais elementos que atua nesse processo, promovendo, de maneira constante, uma relação entre formação e remoção de material (WERLANG, 2004).

O processo erosivo causado pela água das chuvas, apesar de ter abrangência em quase toda a superfície terrestre, ocorre em especial nas áreas tropicais. Werlang (2004) observa que a erosão se torna um problema no momento em que o equilíbrio entre formação e remoção é rompido e a erosão se torna acelerada.

Conforme Guerra (2007), a primeira etapa do processo erosivo é a ruptura dos agregados do solo. Isso acontece basicamente através da ação do splash. A ação deste ocorre principalmente através das gotas da chuva, causando, além da ruptura dos agregados, também a quebra das partículas do solo. A partir desse momento, com a presença de partículas menores, ocorre o preenchimento dos espaços porosos do solo, podendo provocar o selamento da camada superficial deste.

A intensidade do splash varia conforme a resistência do solo ao impacto das gotas de chuva e à própria energia cinética das gotas de chuva, (GUERRA, 2007). Essa energia cinética é, segundo Goudie (1985 apud Guerra, 2007), resultante do movimento translacional de um corpo, e altamente significante para erosão, pois envolve gasto de energia para a ruptura dos agregados e para o splash das partículas. Assim, Guerra 
(2007) coloca que a energia cinética está intrinsecamente relacionada à intensidade da chuva, sendo uma função da sua duração, massa, tamanho e velocidade da gota de chuva.

Já quanto à estabilidade dos agregados, esta está diretamente relacionada a diversos fatores, como a textura, densidade aparente, porosidade, estrutura, cobertura vegetal, uso e manejo do solo, além do teor de matéria orgânica, sendo este um dos mais importantes em qualquer pesquisa relacionada à erosão (GUERRA, 2007). Posteriormente à ruptura dos agregados e das partículas do solo através do splash, acontece o selamento do solo, que vai depender principalmente da intensidade da chuva e também do transporte dessas partículas. Para Guerra (2007), o selamento ocorre através do preenchimento dos espaços porosos e da consequente diminuição da infiltração, acarretando também o início do escoamento superficial. O que ocorre nessa etapa é, na verdade, uma mudança de processos: primeiro ocorre grande destacamento e baixo transporte, depois baixo destacamento e alto transporte, iniciando-se, assim, o processo erosivo. Com relação a isso, Guerra (2007) destaca que, à medida que a resistência à ação do splash aumenta, com a destruição dos agregados e o selamento superficial do solo, aumenta também a ação do escoamento superficial (Runoff).

Outro fator importante para a ocorrência do processo erosivo, e também para melhor entendê-lo, é a infiltração. A quantidade de água que irá se infiltrar no solo em um determinado tempo exercerá influência direta na ocorrência do escoamento superficial.

Primeiramente, pode-se afirmar que a infiltração de água no solo vai depender das propriedades dos solos, da cobertura vegetal, uso e manejo do solo. A água percola os espaços porosos do solo até o momento da saturação deste, sendo essa saturação dependente, além das condições já citadas, também da umidade presente no solo, anteriormente ao evento chuvoso. Após a saturação de água no solo, ocorre a formação de poças de água, que, quando interligadas, provocarão o início do escoamento. É importante destacar ainda que a saturação do solo poderá ser antecipada, em função da possível ocorrência da selagem, principalmente em eventos pluviométricos muito intensos (GUERRA, 2007).

Dessa forma, inicia-se o processo erosivo que será, num primeiro momento, laminar, carregando diversas partículas no fluxo erosivo. Nesse primeiro estágio, a área abrangida é maior, com relação às etapas seguintes. 


\subsection{A erosão laminar}

Em função de área de estudo estar situada numa planície de inundação e pela razão de apresentar relevo com topografia plana à suavemente ondulada, apresenta alta susceptibilidade à erosão laminar, uma vez que não apresenta o desenvolvimento de fluxo linear de alto poder erosivo.

A erosão laminar, em muitos casos, é apenas o primeiro estágio de desenvolvimento da erosão. Porém, na área de estudo, essa é a principal forma de erosão atuante que ocorre de maneira mais ou menos intensa, conforme as seguintes características da energia cinética da chuva (erosividade da chuva): cobertura vegetal, que envolve basicamente a proteção do solo e o aumento da infiltração além das propriedades dos solos (Gleissolos e Planossolos).

A erosão laminar, pela sua característica, é de difícil percepção. A curto prazo, torna-se menos perceptível na paisagem, podendo, dessa forma, carregar uma quantidade de solo muito grande até ser percebida. Assim, é possível afirmar que essa forma de erosão é uma das mais degradantes, além de representativa no carregamento de nutrientes e de matéria orgânica, pois retira uma grande quantidade da camada superficial do solo, causando, dessa forma, degradação da estrutura física do solo e também perda da sua fertilidade natural.

\subsection{Os Planossolos}

A área de estudo, situada na várzea do rio Jacuí, na localidade denominada Várzea do Agudo, recebe a contribuição direta desse rio na deposição de diversos tipos de sedimentos que vão se alocar na planície aluvial. Assim, a área da localidade está situada numa área de depósitos aluvionares de planície da Era Cenozóica, caracterizados por cascalho marrom, sustentado pelos clastos compostos, desde areia fina até areia grossa, que são maciços e com laminação cruzada de porte médio, além de lama preta e cinza-escuro maciça e com restos de vegetais e artrópodes, associadas à planície de inundação.

Portanto, face à deposição sedimentar aluvionar relacionada a material de origem da Formação Santa Maria (Membro Alemoa), nas baixadas, várzeas e depressões, sob condições de umidade, os Planossolos ocorrem sob condições de hidromorfismo, possuindo horizonte B plânico que apresenta coincidentemente características de horizonte glei. 
Assim, os Planossolos, segundo a Embrapa (2006, p.94), são denominados:

\begin{abstract}
solos minerais imperfeitamente ou mal drenados, com horizonte superficial ou subsuperficial eluvial, de textura mais leve, que contrasta abruptamente com o horizonte B ou com transição abrupta conjugada com acentuada diferença de textura do A para o horizonte B imediatamente subjacente, adensado, geralmente de acentuada concentração de argila, permeabilidade lenta ou muito lenta, constituindo, por vezes, um horizonte plânico, responsável pela formação de lençol d'água sobreposto (suspenso), de existência periódica e presença variável durante o ano.
\end{abstract}

Dessa forma, é possível perceber que este solo tem características relacionadas à pouca permeabilidade, sendo, portanto, muito propício ao desenvolvimento de culturas que necessitam de muita água, como o arroz irrigado.

Com relação a algumas propriedades morfológicas de um planossolo, este se caracteriza, em geral, pela seguinte sequência de horizontes: horizonte A, AB ou A, E (este pode ser álbico ou não) ou Eg, seguidos de Bt, Btg, Btn ou Btng. Uma das características mais notáveis é a transição abrupta existente entre os horizontes superficial A e o subsequente (B ou E), apresentando também grande diferença de textura entre os horizontes. Outra característica notável é que os horizontes subsuperficiais costumam possuir altos teores de argila dispersa, além da presença de uma estrutura forte em blocos angulares, frequentemente com aspecto cúbico ou então estrutura prismática ou colunar, pelo menos na parte superior do horizonte, que geralmente é o B (EMBRAPA, 2006). Além disso, outra característica é a presença ou não de horizonte cálcico, com caráter carbonático, duripã, propriedade sódica, solódica, caráter salino ou sálico. Pode ainda ocorrer a presença de plintita, porém, esta deve estar em quantidade ou em posição não diagnóstica para enquadramento na classe dos Plintossolos.

\title{
3. Metodologia
}

Para o desenvolvimento do trabalho, adotou-se a orientação metodológica da proposta de análise sistêmica da paisagem (Sochava, 1972; Bertrand, 1968, 197; Monteiro, 2000) e dos níveis de tratamento definidos por Ab'Saber (1969). 
Classificados em grupos epistemológicos, os métodos podem ser indutivos, dedutivos, hipotético-dedutivo, dialético e fenomenológico. Para realização deste trabalho, fez-se uso do método dedutivo, acreditando-se ser esta uma das formas que permite uma maior proximidade da realidade com a pesquisa. Proposto por Popper, esse método consiste na adoção da seguinte linha de raciocínio, conforme Gil (1999, p.30):

\begin{abstract}
quando os conhecimentos disponíveis sobre determinado assunto são insuficientes para a explicação de um fenômeno, surge o problema. Para tentar explicar as dificuldades expressas no problema, são formuladas conjecturas ou hipóteses. Das hipóteses formuladas, deduzem-se conseqüências que deverão ser testadas ou falseadas. Falsear significa tornar falsas as conseqüências deduzidas das hipóteses. Enquanto no método dedutivo se procura a todo custo confirmar a hipótese, no método hipótetico-dedutivo, ao contrário, procuram-se evidências empíricas para derrubá-la" .
\end{abstract}

Buscou-se, portanto, abordar elementos relevantes para o estudo em questão. Assim, foram coletadas amostras (deformadas e indeformadas) em doze pontos na área da Várzea do Agudo. Seis em área de lavoura e seis em área de mata. Uma vez identificada no perfil do solo a presença do horizonte pedogenético $\mathrm{A}$, as amostras foram coletadas a $15 \mathrm{~cm}$ de profundidade.

Com base em referencial teórico e na análise dos resultados obtidos a partir dos ensaios realizados, no campo e em laboratório e, levando-se em consideração o uso e manejo do solo em cada ponto, foi realizada a análise acerca da erosão laminar, junto à área da localidade de Várzea do Agudo.

Como no estudo foi feita uma análise comparativa entre uma área de lavoura e outra de mata, considera-se importante a colocação acerca do conceito adotado para mata e lavoura. Assim, entendeu-se por mata toda e qualquer vegetação de porte arbustivo, médio e alto, composta por vegetação nativa ou secundária. Nesse conceito foram enquadradas matas que possuem pelo menos quinze anos sem corte raso. É importante ainda destacar que as áreas de pastagens, vegetação rasteira e vegetação exótica, como eucaliptos, foram desconsideradas no momento da coleta das amostras. Como lavoura, entendeu-se toda e qualquer área destinada ao plantio de arroz, áreas estas que possuem este uso há pelo menos quinze anos.

Em todos os pontos amostrados, tomou-se como cuidado considerar que todos apresentassem características muito semelhantes quanto à geomorfologia. Também, todas as coletas de amostras foram feitas 
sob condições atmosféricas de tempo bom e com o solo apresentando condições de umidade que permitissem a coleta de amostras indeformadas. As coletas foram realizadas na primavera de 2009. A figura 2 mostra a área da Várzea do Agudo e a figura 3 mostra os locais onde foram selecionados os pontos e retiradas das amostras.

Os ensaios foram realizados no laboratório de sedimentologia do Departamento de Geociências da Universidade Federal de Santa Maria. Os ensaios de infiltração foram realizados no campo, com base na metodologia proposta por Netto; Avelar (1996).

Os parâmetros físicos determinados foram a distribuição do tamanho de partículas (análise granulométrica), estabilidade de agregados, densidade de partículas $(\gamma s)$, densidade aparente $(\gamma d)$, teor de matéria orgânica, coeficiente de infiltração $(C i)$, índice de vazios (e) e porosidade total (Pt). Foram coletadas amostras deformadas ${ }^{2}$ com 500 g de cada um dos pontos para a determinação do tamanho de partículas, da estabilidade de agregados e do teor de matéria orgânica. Além dessas, foram coletadas, nos mesmos pontos, amostras indeformadas ${ }^{3}$ para a determinação da densidade aparente do solo.

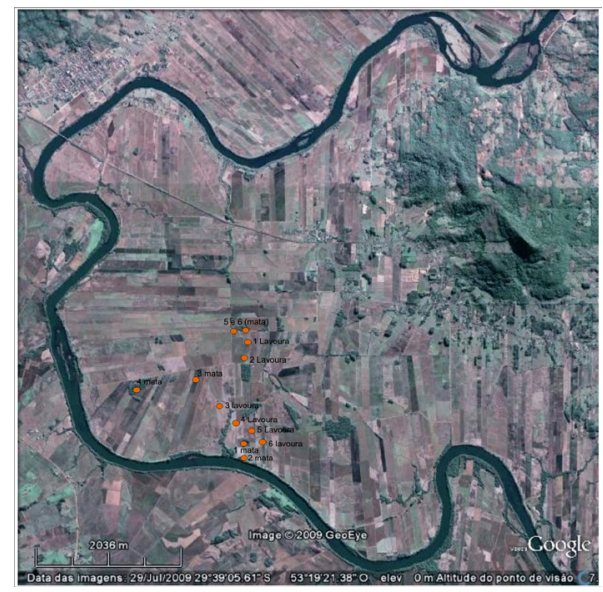

Figura 2. Área parcial da localidade Várzea do Agudo e localização dos pontos de coleta de amostras, visualizados a partir da imagem Google Earth Fonte: www.google.com.br/intl/pt-BR/earth/.../ge/agree.html (adaptado).

\footnotetext{
${ }^{2}$ As amostras deformadas foram coletadas e armazenadas em saco plástico.

${ }^{3}$ As amostras indeformadas foram coletadas em anéis de ferro com volume e peso conhecido.
} 


\section{ciência'natura UFSM, 34(2)}

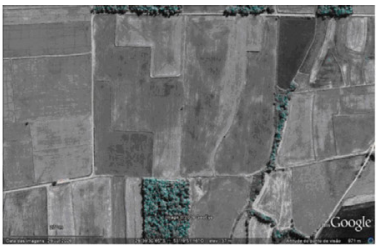

Ponto 1 e 2 área de lavoura

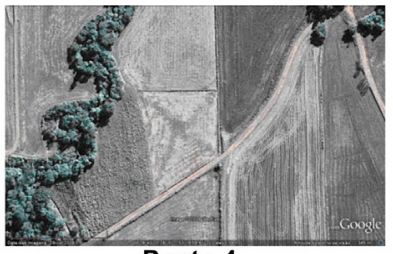

Ponto 4 área de lavoura

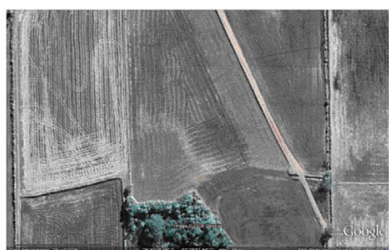

Ponto 6

área de lavoura

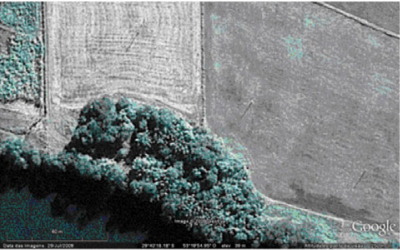

Ponto 8 área de mata

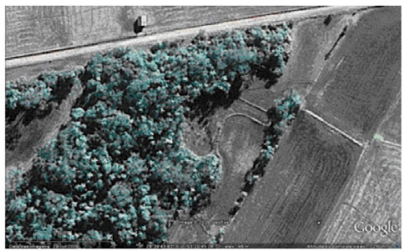

Ponto 10 área de mata

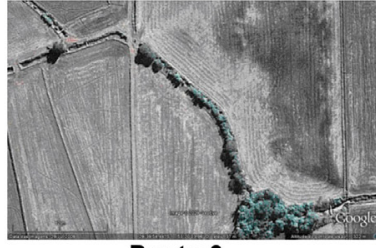

Ponto 3

área de lavoura

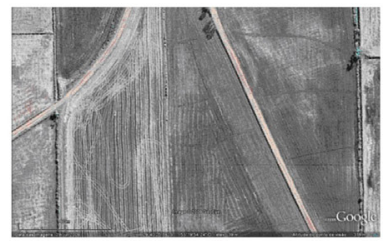

Ponto 5

área de lavoura

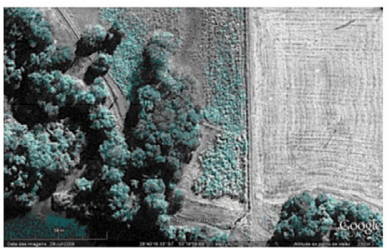

Ponto 7 área de mata

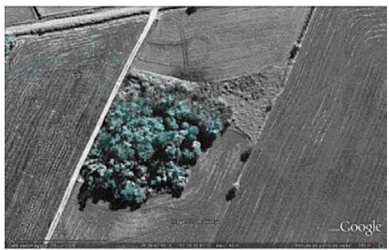

Ponto 9

área de mata

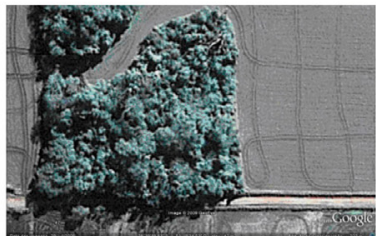

Ponto 11 e 12

área de mata

Figura 3. Localização dos pontos de coleta das amostras, visualizada a partir da imagem Google Earth.

Fonte: www.google.com.br/intl/pt-BR/earth/.../ge/agree.html (adaptado) 
O ensaio de infiltração foi realizado nos mesmos pontos onde foram coletadas as amostras, a partir da superfície do solo (horizonte pedogenético A) e foram observadas as quantidades infiltradas conforme os tempos pré-determinados para o método. O cálculo para a determinação do coeficiente de infiltração se deu pela aplicação das equações 1 e 2, conforme Netto; Avelar (1996):

$\mathrm{Q}=\mathrm{fj} / \mathrm{fjt}$ (equação 1)

$C i=\mathrm{Q} /$ Acil (equação 2)

em que:

$\mathrm{Q}=$ vazão;

fjv = variação de volume de água;

fit $=$ variação de tempo;

$C i$ coeficiente de infiltração;

Acil $=$ área do cilindro.

Para a determinação da densidade aparente, foi empregada a equação 3 (Caputo, 1981):

$\gamma d=\mathrm{Mss} / \mathrm{Vs}$

(equação 3)

em que:

$\gamma d$ = densidade aparente do solo;

Mss = massa de solo seco;

$\mathrm{Vs}=$ volume de solo.

Na determinação da densidade de partículas ou real, foi utilizada a equação 4 (Donuhue,1952):

$\gamma s=$ Ps $/$ Val (equação 4) em que:

$\gamma s=$ densidade de partículas;

Ps = peso do solo;

$\mathrm{Val}=$ volume de álcool gasto.

Para a determinação da granulometria dos sedimentos finos, foi utilizado o método da sedimentação e, para as areias, o peneiramento, conforme determinações da ABNT/NBR 7181/82.

Para a obtenção do índice de vazios, foi utilizada a equação 5 (Caputo,1981): 
$e=(\gamma s / \gamma d)-1$

(equação 5)

em que:

$e=$ índice de vazios;

$\gamma s=$ densidade de partículas;

$\gamma d=$ densidade aparente.

Com relação à porosidade total, a determinação foi obtida com base na equação 6 (Caputo, 1981):

$P t=e /(1+e)$

(equação 6)

em que:

$P t=$ porosidade total;

$e=$ índice de vazios.

Para a determinação do teor de matéria orgânica, foi utilizado o método da perda de peso por ignição, conforme equação 7 (Combs; Nathan,1998; Cambardella et al., 2001; konen et al. 2002 apud Escosteguy, 2007):

$\mathrm{MO}=\left(\operatorname{Pcad}+\mathrm{S} 105^{\circ}, 2 \mathrm{~h}\right)-\left(\operatorname{Pcad}+\mathrm{S} 360^{\circ}, 2 \mathrm{~h}\right) /\left(\operatorname{Pcad}+\mathrm{S} 105^{\circ}, 2 \mathrm{~h}\right)-(\operatorname{Pcad}$ $\left.360^{\circ}, 2 \mathrm{~h}\right) * 100$

(equação 7)

em que:

$\mathrm{MO}=$ matéria orgânica;

Pcad = peso cadinho (forma de porcelana em que é armazenada a amostra);

$\mathrm{S}=$ solo.

Para a determinação da estabilidade dos agregados, foi utilizada a equação 8:

$\mathrm{EA}(\%)=\{[(\mathrm{mAGR})] /(\mathrm{Xg}-\mathrm{mA}-\mathrm{mAR})\} * 100$

(equação 8)

em que:

$\mathrm{EA}=$ estabilidade de agregados;

$\mathrm{mAGR}=$ massa de agregados;

$\mathrm{Xg}=$ quantidade da amostra utilizada no ensaio (peso da cápsula - cápsula + solo);

$\mathrm{mA}=$ massa de areias;

$\mathrm{mAR}=$ massa de água residual nos 4 gramas da amostra. 


\section{Resultados e Discussão}

Depois de obtidas as determinações, a partir dos ensaios realizados, partiu-se para a análise dos resultados, buscando-se estabelecer a relação entre os resultados e a avaliação da erosão laminar. Ao buscar um melhor entendimento para a análise dos resultados, estes foram divididos em três conjuntos. $\mathrm{O}$ primeiro deles foi o referente à granulometria; o segundo, esteve relacionado à densidade aparente, à densidade de partículas, ao índice de vazios e à porosidade total e, por último, à estabilidade dos agregados e à matéria orgânica. Ao final, esses dados foram relacionados com o coeficiente de infiltração, uma vez que exercem influência sobre ele.

Em face da ocorrência da erosão estar também relacionada à ação antrópica, iniciou-se a análise a partir da distribuição do tamanho de partículas. A tabela 1 mostra os resultados obtidos para a área de lavoura e a tabela 2, para a área com mata. As figuras 4 e 5 trazem as curvas graulométricas obtidas.

Tabela 1: Várzea do Agudo - distribuição do tamanho de partículas e classe textural das amostras relativas à área de lavoura.

\begin{tabular}{ccccc}
\hline $\begin{array}{c}\text { Ponto/ } \\
\text { amostrado }\end{array}$ & Areia (\%) & Silte (\%) & Argila (\%) & $\begin{array}{c}\text { Classe } \\
\text { textural }\end{array}$ \\
\hline 1 & 12,45 & 39,64 & 47,77 & Argila \\
2 & 22,45 & 32,81 & 44,73 & Argila \\
3 & 9,16 & 40,14 & 50,70 & Argila siltosa \\
4 & 29,53 & 27,96 & 42,51 & Argila \\
5 & 16,37 & 35,59 & 48,04 & Argila \\
6 & 13,21 & 37,91 & 48,87 & Argila \\
\hline
\end{tabular}

Fonte: Coleta de campo e ensaios em laboratório. Setembro de 2009 .

Tabela 2: Várzea do Agudo - distribuição do tamanho de partículas e classe textural das amostras relativas à área de mata.

\begin{tabular}{|c|c|c|c|c|}
\hline $\begin{array}{c}\text { Ponto/ } \\
\text { amostrado }\end{array}$ & Areia (\%) & Silte (\%) & Argila (\%) & $\begin{array}{c}\text { Classe } \\
\text { textural }\end{array}$ \\
\hline 7 & 10,00 & 46,19 & 43,81 & Argila siltosa \\
\hline 8 & 26,41 & 37,20 & 36,38 & $\begin{array}{c}\text { Franco } \\
\text { argilosa }\end{array}$ \\
\hline 9 & 8,30 & $5^{1,}, 63$ & 41,07 & Argila siltosa \\
\hline 10 & 5,09 & 49,71 & 45,20 & Argila siltosa \\
\hline 11 & 1,81 & 47,50 & 50,69 & Argila siltosa \\
\hline 12 & 13,94 & 45,04 & 41,02 & Argila siltosa \\
\hline
\end{tabular}

Fonte: Coleta de campo e ensaios em laboratório. Setembro de 2009. 


\section{ciência'natura UFSM, 34(2)}

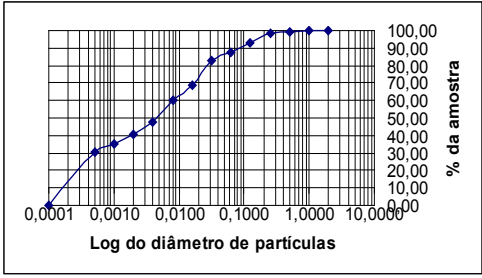

Ponto/amostrado 1

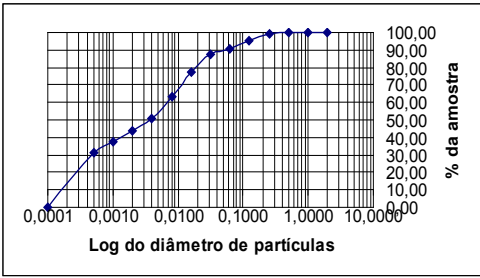

Ponto/amostrado 3

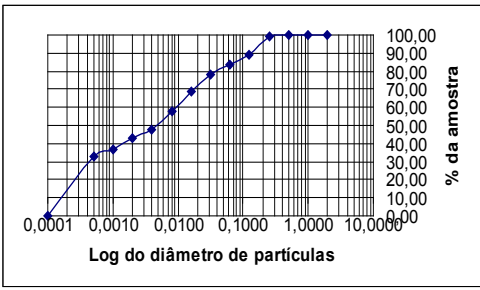

Ponto/amostrado 5

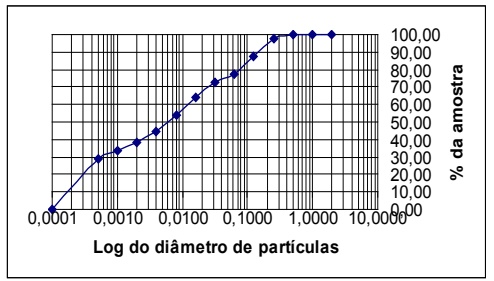

Ponto/amostrado 2

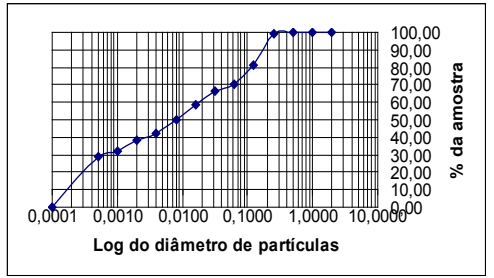

Ponto/amostrado 4

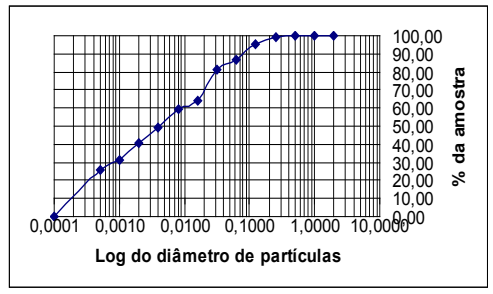

Ponto/amostrado 6

Figura 4: Várzea do Agudo - Curvas granulométricas obtidas das amostras relativas à área de lavoura.

Fonte: Coleta de campo e ensaios em laboratório. Setembro de 2009.

Observando a distribuição do tamanho de partículas, nota-se que a fração areia apresenta maiores teores na área relativa à lavoura. A fração silte predomina na área de mata. O enquadramento no triângulo textural revela que, na área com lavoura, predomina a classe argila e, para área com mata, a argila siltosa. 


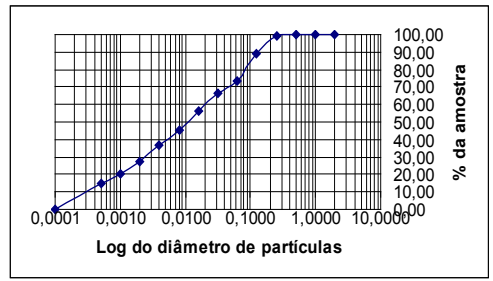

Ponto/amostrado 7

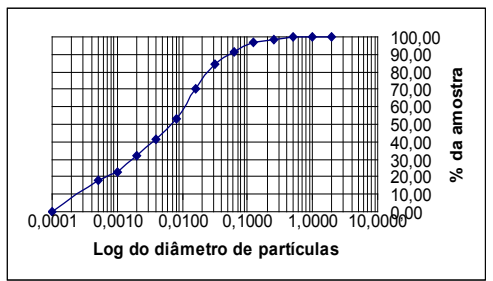

Ponto/amostrado 9

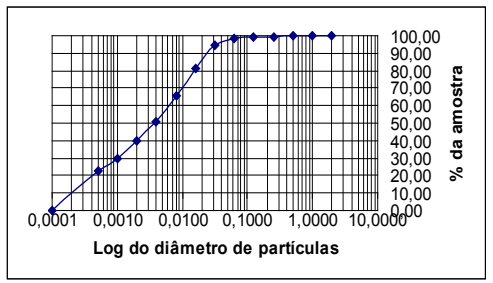

Ponto/amostrado 11

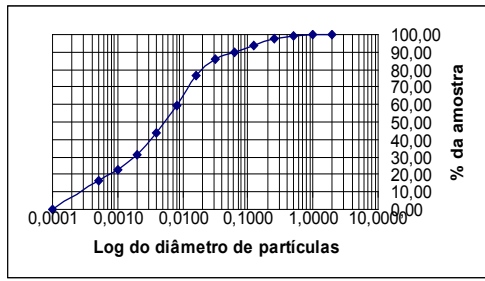

Ponto/amostrado 8

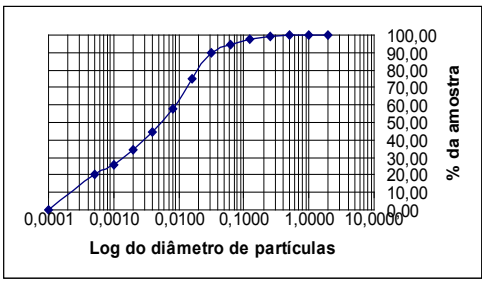

Ponto/amostrado 10

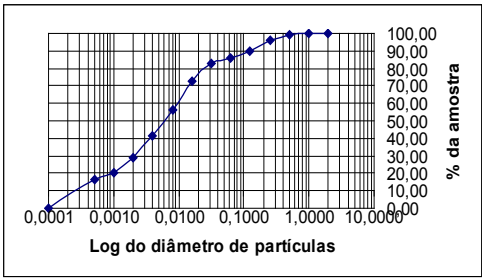

Ponto/amostrado 12

Figura 5: Várzea do Agudo - Curvas granulométricas obtidas das amostras relativas à área de mata

Fonte: Coleta de campo e ensaios em laboratório. Setembro de 2009.

As curvas granulométricas revelam um material mal graduado, cujo diâmetro efetivo $\mathrm{D}_{50}$ está na fração silte. Isso revela que a área é muito suscetível á erosão hídrica. Está bastante vulnerável ao efeito de lavagem, tanto pela composição granulométrica como pela localização das lavouras na área da várzea do rio Jacuí. O rio é o principal elemento que carrega as partículas para as áreas adjacentes a várzea. Essas áreas de lavoura também sofreram processo de manejo para o cultivo do arroz pré-germinado e, em muitos casos, houve revolvimento dos horizontes superficiais do solo. Ainda com relação ao comportamento das curvas 
granulométricas, pode-se observar que, para a área de mata, elas apresentam uma melhor graduação.

O predomínio da fração silte e argila está relacionado à característica dos Planossolos que ocorrem na área, e cujo material de origem está ligado à Formação Santa Maria (Membro Alemoa). Ainda essa composição granulométrica tem relação com o efeito da deposição fluvial, pois a área da Várzea do Agudo sofre a ação da deposição aluvionar desde a Era Cenozoica.

Ao analisar a densidade do solo, é importante lembrar que expressa a razão da massa pelo volume da amostra, estando esse índice muito relacionado ao uso e manejo do solo, além de poder ser relacionada diretamente com a compactação do solo. Dessa forma, também tem relação direta com o coeficiente de infiltração.

As tabelas 3 e 4 mostram os resultados obtidos para a densidade aparente, densidade de partículas, índice de vazios e porosidade total para as duas áreas amostradas.

Tabela 3: Várzea do Agudo - resultados obtidos para a densidade aparente, densidade de partículas, índice de vazios e porosidade total para a área de lavoura.

\begin{tabular}{ccccc}
\hline $\begin{array}{c}\text { Pontos } / \\
\text { amostrados }\end{array}$ & $\gamma s\left(\mathrm{~g} / \mathrm{cm}^{3}\right)$ & $\gamma d\left(\mathrm{~g} / \mathrm{cm}^{3}\right)$ & $e$ & $P t(\%)$ \\
\hline 1 & 2,610 & 1,267 & 1,06 & 51,4 \\
2 & 2,628 & 1,314 & 1,00 & 50,0 \\
3 & 2,564 & 1,075 & 1,39 & 58,1 \\
4 & 2,562 & 1,399 & 0,83 & 45,3 \\
5 & 2,484 & 1,076 & 1,31 & 56,7 \\
6 & 2,480 & 1,260 & 0,98 & 49,5 \\
\hline
\end{tabular}

Fonte: Coleta de campo e ensaios em laboratório. Setembro de 2009.

Tabela 4: Várzea do Agudo - resultados obtidos para a densidade aparente, densidade de partículas, índice de vazios e porosidade total para a área de mata.

\begin{tabular}{ccccc}
\hline $\begin{array}{c}\text { Pontos } / \\
\text { amostrados }\end{array}$ & $\left.\gamma s \mathrm{~g} / \mathrm{cm}^{3}\right)$ & $\gamma d\left(\mathrm{~g} / \mathrm{cm}^{3}\right)$ & $e$ & $P t(\%)$ \\
\hline 7 & 2,330 & 1,264 & 1,89 & 65,4 \\
8 & 2,218 & 0,804 & 1,75 & 63,6 \\
9 & 2,253 & 0,908 & 1,48 & 59,6
\end{tabular}


Continuação Tabela 4

\begin{tabular}{ccccc}
\hline Pontos $/$ & $\left.\gamma S \mathrm{~g} / \mathrm{cm}^{3}\right)$ & $\gamma d\left(\mathrm{~g} / \mathrm{cm}^{3}\right)$ & $e$ & $P t(\%)$ \\
amostrados & 2,310 & 1,016 & 1,27 & 56,0 \\
10 & 2,121 & 0,921 & 1,30 & 56,5 \\
11 & 2,173 & 0,921 & 1,35 & 57,5 \\
12 &
\end{tabular}

Fonte: Coleta de campo e ensaios em laboratório. Setembro de 2009.

Os resultados mostram que a densidade aparente foi maior para as amostras da área de lavoura, refletindo nos resultados obtidos para o índice de vazios e porosidade. Isso demonstra um impacto maior, causado nessas propriedades para o manto superficial do solo para área ocupada com lavoura.

Ao confrontarem-se esses dados com os obtidos a partir dos ensaios de infiltração, é possível observar que ocorre uma menor infiltração nas áreas de lavoura. Isso está associado ao uso e manejo do solo e ao escoamento superficial. As tabelas 5 e 6 trazem os resultados obtidos para o coeficiente de infiltração.

Tabela 5: Várzea do Agudo - resultados obtidos para os ensaios de infiltração para a área de lavoura.

\begin{tabular}{cc}
\hline Pontos/amostrados & $\begin{array}{c}\text { Coeficiente de } \\
\text { infiltração }(\mathrm{cm} / \mathrm{h})\end{array}$ \\
\hline 1 & 1,2 \\
2 & 0,6 \\
3 & 0,6 \\
4 & 0,6 \\
5 & 4,8 \\
6 & 6,0 \\
\hline
\end{tabular}

Fonte: Coleta de campo e ensaios em laboratório. Outubro de 2009.

Tabela 6: Várzea do Agudo - resultados obtidos para os ensaios de infiltração para a área de mata.

\begin{tabular}{cc}
\hline Pontos/amostrados & $\begin{array}{c}\text { Coeficiente de } \\
\text { infiltração }(\mathrm{cm} / \mathrm{h})\end{array}$ \\
\hline 7 & 6,0 \\
8 & 42.0 \\
9 & 12,0 \\
10 & 12,0
\end{tabular}




\begin{tabular}{cc} 
Continuação Tabela 6 & \\
\hline Pontos/amostrados & $\begin{array}{c}\text { Coeficiente de } \\
\text { infiltração }(\mathrm{cm} / \mathrm{h})\end{array}$ \\
11 & 18,0 \\
12 & 12,0 \\
\hline
\end{tabular}

Fonte: Coleta de campo e ensaios em laboratório. Outubro de 2009.

Em relação à estabilidade dos agregados e aos teores de matéria orgânica, as tabelas 7 e 8 mostram os resultados obtidos. Constata-se a diferença existente entre o solo em área de lavoura, comparado a um solo em área de mata. Na área ocupada com mata, os agregados mostram-se mais estáveis. Também fica evidente a relação direta com o teor de matéria orgânica presente em maior proporção na área ocupada com mata. Ainda é importante destacar que, na área com lavoura, o trânsito de máquinas e implementos agrícolas interfere na compactação e na estrutura do solo.

Quanto ao comportamento do coeficiente de infiltração, os dados obtidos revelam que também há relação direta, notando-se maior infiltração nas áreas cuja estrutura está melhor preservada e, menor infiltração, na área ocupada por lavoura, cuja estabilidade dos agregados foi menor. O coeficiente de infiltração foi maior em áreas de mata. Os dados revelaram também uma maior estabilidade de agregados para área de mata, quando comparada á área ocupada por lavoura.

Tabela 7: Várzea do Agudo - resultados obtidos para os ensaios de estabilidade dos agregados e matéria orgânica para a área ocupada com lavoura.

\begin{tabular}{ccc}
\hline Pontos/amostrados & $\begin{array}{c}\text { Estabilidade de } \\
\text { agregados (\%) }\end{array}$ & MO (\%) \\
\hline 1 & 38,79 & 2,29 \\
2 & 34,55 & 2,38 \\
3 & 45,37 & 2,40 \\
4 & 24,66 & 2,77 \\
5 & 33,23 & 2,58 \\
6 & 61,65 & 2,83 \\
\hline
\end{tabular}

Fonte: Coleta de campo e ensaios em laboratório. Outubro de 2009. 
Tabela 8: Várzea do Agudo - resultados obtidos para os ensaios de estabilidade dos agregados e matéria orgânica para a área ocupada com mata.

\begin{tabular}{ccc}
\hline Pontos/amostrados & $\begin{array}{c}\text { Estabilidade de } \\
\text { agregados (\%) }\end{array}$ & MO (\%) \\
\hline 7 & 71,91 & 3,87 \\
8 & 91,30 & 5,19 \\
3 & 85,89 & 4,70 \\
10 & 86,59 & 5,75 \\
11 & 96,01 & 5,13 \\
12 & 92,56 & 5,34 \\
\hline
\end{tabular}

Fonte: Coleta de campo e ensaios em laboratório. Outubro de 2009.

Mitchell; Bubenzer (1980), Veiga; Cabeda; Reichert (1993), Azevedo; Kaminski (1995), Salomão (1999) e Schäfer et al. (2001) destacam algumas propriedades do solo que reconhecidamente afetam a sua erodibilidade. Entre elas estão a textura, o teor de matéria orgânica, a estrutura do solo, os óxidos de ferro e alumínio além da mineralogia e do grau de intemperismo. Destacam também que baixos teores de argila e de matéria orgânica conferem um caráter débil de resistência aos processos erosivos.

O coeficiente de infiltração é, portanto, um índice importante, uma vez que a erosão começa a ser um problema no momento em que o transporte de material excede aquele que é fornecido pela intemperização ou quando há grande acúmulo de sedimentos, provocando assoreamento. Isso ocorre principalmente pela ação das águas correntes superficiais.

\section{Conclusão}

Ao observar a distribuição do tamanho de partículas, nota-se que a fração areia apresenta maiores teores na área relativa à lavoura e a fração silte predomina na área ocupada por mata. Predomina na área com uso de lavoura a classe textural argila e, para área com mata, argila siltosa.

As curvas granulométricas revelam um material mal graduado, cujo diâmetro efetivo $\mathrm{D}_{50}$ está na fração silte, indicando que a área é muito suscetível á erosão hídrica. Além disso, é também bastante vulnerável ao efeito de lavagem, tanto pela sua composição granulométrica como pela localização das lavouras na área da várzea do rio Jacuí. 
A densidade aparente foi maior para as amostras da área de lavoura, refletindo nos resultados obtidos para o índice de vazios e porosidade. Isso demonstra um impacto maior causado ao horizonte superficial. Ao confrontarem-se esses dados com os obtidos nos ensaios de infiltração, é possível observar que ocorre uma menor infiltração nas áreas de lavoura e maior em áreas de mata. Além disso, a área com mata apresentou maior teor de matéria orgânica e maior estabilidade de agregados, quando comparada à área ocupada por lavoura. Isso está associado ao uso e manejo dado ao solo.

A área refere-se à acumulação colúvio-aluvionar, localmente caracterizada por sedimentos argilo-siltosos, argilosos e arenosos. Engloba as formas originadas por processos de coluviação e de deposição fluvial onde se encontram sedimentos detríticos pouco consolidados, caracterizando feições do domínio geomorfológico da Depressão Periférica Sul-riograndense, onde ocorrem preferencialmente os Planossolos.

\section{Referências}

AB'SABER, A.N. Um conceito de geomorfologia a serviço das pesquisas sobre o Quaternário. Geomorfologia, São Paulo, n.18, 1969.

ASSOCIAÇÃO BRASILEIRA DE NORMAS TÉCNICAS. Determinação da distribuição do tamanho de Partículas: ABNT/NBR 7181/82. Rio de Janeiro, 1992.

AYOADE, J. Introdução a climatologia dos trópicos. São Paulo: Difel, 1986.

AZEVEDO, A. C. Funções Ambientais do Solo. SOlOS E AMBIENTE. FORUM I, 1.,2004, Santa Maria. Anais... Santa Maria: Pallotti, 2004.p.21.

AZEVEDO, A.C.; DALMOLIN, R. S. D. Solos e Ambiente: uma introdução. Santa Maria: Pallotti, 2006.

AZEVEDO, A.C.; KAMINSKI, J. Considerações sobre os solos dos campos de areia no Rio Grande do Sul. Revista Ciência \& Ambiente. Santa Maria: Editora da Universidade Federal de Santa Maria, n. 11, p. 33-55, jul./dez. 1995 . 
BERTONI, J. ; LOMBARDI NETTO, F. Conservação do Solo. São Paulo: Ícone, 1990.

BERTRAND, G. Paysage et géographie physique globale: Esquisse méthodologique. Revue Géographique des Pyrénées et du Sud-Ovest, Toulouse: v 3, n. 39, p. 249-272,1968.

CAPUTO, H. P. Mecânica dos Solos e suas aplicações. Rio de Janeiro: Livros Técnicos e Científicos S.A., 1981.

EMBRAPA. Sistema Brasileiro de Classificação de Solos. Rio de Janeiro: EMBRAPA-SPI, 2 Ed., 2006. 399p.

ESCOSTEGUY, P.A.V.; GALLIASSI, K. CERETTA, C.A. Determinação de matéria orgânica do solo pela perda de massa por ignição, em amostras do Rio Grande do Sul. Revista Brasileira de Ciência do Solo, v. 31, p. $247-255,2007$.

FIBGE-FUNDAÇÃO INSTITUTO BRASILEIRO DE GEOGRAFIA E ESTATÍSTICA. Projeto RADAMBRASIL. Folha SH-21. Rio de Janeiro: FIBGE, v. 33, 1986.

FONSECA, A. do C. Geoquímica dos solos. In: GUERRA, A.J.T; SILVA, A.S.; BOTELHO, R.G.M. (orgs.) Erosão e conservação dos solos:conceitos, temas e aplicações. Rio de Janeiro: Bertrand Brasil, 1999.

GIL, A.C. Métodos e técnicas de pesquisa social. São Paulo: Atlas, 1999. Disponível em: http://pt.scribd.com/doc/2367267/DA-SILVA-MENEZES-2001-Metodologia-da-pesquisa-e-elaboracao-de-dissertacao Acesso em: 08 de julho de 2011.

GOOGLE EARTH. Disponível em: www.google.com.br/intl/pt-BR/earth/.../ge/agree.html Acesso em: 08 de novembro de 2008.

GUERRA, A.J.T. O início do processo erosivo. In: Erosão e Conservação dos Solos: Conceitos, Temas e Aplicações. 3 Ed. Rio de Janeiro: Bertrand Brasil, 2007. Cap. 1, p. 17-55.

INSTITUTO BRASILEIRO DE GEOGRAFIA E ESTATÍSTICA - IBGE. Disponível em: <http://ibge.gov.br >. Acesso em: o8 de novembro de 2010. 
JENNY, H. Factors of soil formation: a systen of quantitative pedology. New York: Dover Publications, INC.,1992. 269p.

KAMINSKI, J. Impactos da Atividade Humana Sobre o Solo: atividades rurais. SOLOS E AMBIENTE FORUM I, 1., 2004, Santa Maria. Anais... Santa Maria: Pallotti, 2004.

MITCHELL, J. K.; BUBENZER, G. D. Estimación de la pérdida del suelo. In: MONTEIRO, C.A.F. Geossistemas: a história de uma procura. São Paulo: Contexto, 2000.

NASCIMENTO, P. C.; GIASSON, E.; INDA, A. V. Aptidão de uso dos solos e meio ambiente. SOLOS E AMBIENTE FORUM I, 1.,2004, Santa Maria. Anais... Santa Maria: Pallotti, 2004.p.48.

NETTO, A.L.C.; AVELAR, A. da S. Hidrologia de Encostas na Interface com a Geomorfologia. In: Geomorfologia: Exercícios, Técnicas e Aplicações. Rio de Janeiro: Bertrand Brasil, 1996. p.03-138.

RESENDE, M.; CURI, N.; REZENDE, S.B.D.; CORRÊA, G.F. Pedologia: Base para distinção de ambientes. Viçosa: NEPUT, 1995. 304p.

ROOS, J. L. S. Geografia do Brasil. São Paulo: Edusp, 1996.

SCHÄFER, M.J.; REICHERT, J.M.; REINERT, D.J.; CASSOL, E. A. Erosão em entressulcos e em sulcos sob diferentes preparos e consolidação do solo. Revista Brasileira de Ciência do Solo, n.25, p. 431-441, 2001.

SALOMÃO, F.X.T. Controle e prevenção dos processos erosivos. In: GUERRA,A.J.T; SILVA, A.S.;BOTELHO,R.G.M.(orgs.) Erosão e conservação dos solos: conceitos, temas e aplicações. Rio de Janeiro: Bertrand Brasil, 1999.

SILVA, J.E.B.; GUERRA, A.J.T. Analise das propriedades dos solos das sub-bacias do rio Tindiba e do Córrego do Catonho, Rio de Janeiro, com fins a identificação de áreas com predisposição à erosão. In: SIMPÓSIO NACIONAL DE CONTROLE DE EROSÃO, 7., 2001, Goiânia. Anais... Goiânia: ABGE, 2001. 
SOCHAVA, B. Geographie und ökologie. Geogr. Mitt., Petermanns, XCVI, p. 89-98, 1972.

VEIGA, M.; CABEDA, M.S.V.; REICHERT, J.M. Erodibilidade em entressulcos dos solos do Rio Grande do Sul. Revista Brasileira de Ciência do Solo., Campinas-SP, v.17,.p.121-128, 1993.

VIEIRA, E.F. Rio Grande do Sul. Geografia física e vegetação. Porto Alegre-RS: Sagra, 1984.

WERLANG, M. K. Configuração da rede de drenagem e modelado do relevo: Conformação da paisagem na zona de transição da bacia do Paraná na Depressão Central do Rio Grande do Sul. 207f.(Tese de Doutorado apresentada ao Curso de Doutorado do Programa de Pós-Graduação Ciência do Solo) - Universidade Federal de Santa Maria, Santa Maria, 2004.

WERLANG, W. História da Colônia Santo Ângelo. Santa Maria: Pallotti, 1995.

Submetido em: 09/08/2011

Aceito em: 02/01/2012 
